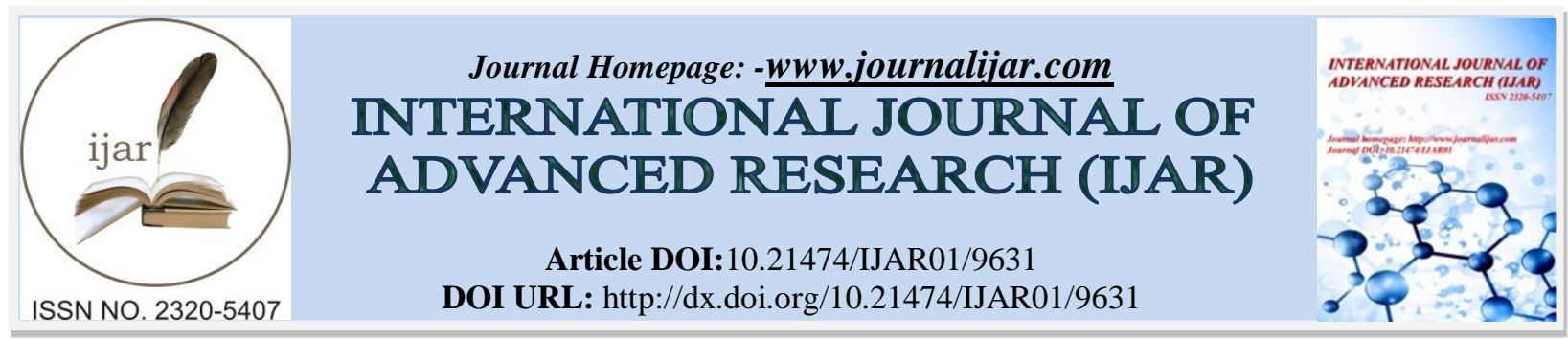

RESEARCH ARTICLE

\title{
KNOWLEDGE ATTITUDE AND PRACTICE OF LIBYAN PHARMACISTS TOWARDS RULES OF PSYCHOTROPIC AND NARCOTIC DRUGS DISPENSING.
}

\section{Arwa Benkhaial ${ }^{1}$, Elzahra Samir Buzariba ${ }^{2}$, Nahla Boushnaf ${ }^{3}$, Rokia Berween $^{4}$, Asma Eljazwi $^{4}$ and Basma Elquzeri ${ }^{4}$.}

1. Lecturer at Department of Pharmacology and Toxicology, Faculty of Pharmacy, University of Benghazi.

2. Assistant Lecturer at Department of Pharmaceutics, Faculty of Pharmacy, University of Benghazi.

3. Department of Clinical Pharmacy at Benghazi Medical Center.

4. Bacholar degree of pharmaceutical sciences, Faculty of Pharmacy, University of Benghazi.

\section{Manuscript Info}

Manuscript History

Received: 02 July 2019

Final Accepted: 04 August 2019

Published: September 2019

Key words:-

Psychotropic drugs, narcotic drugs, dispensing.

\section{Abstract}

Psychotropic and narcotic drugs abuse and misuse are among the most growing problems in Libya and worldwide, that is why they must be strictly prescribed and dispensed. Since the pharmacist has the major role in dispensing and controlling psychotropic and narcotic drugs, we aimed in this study to assess the knowledge, attitude and practice of the Libyan pharmacists towards psychotropic and narcotic drug dispensing. An online questionnaire was spread using social network groups, the questionnaire included 10 items about the dispensing of psychotropic drugs and demographic information of the responding pharmacists. The purpose of these questions was to find out if certain problems regarding psychotropic drugs dispensing occurred in pharmacy practice and how pharmacists dealt with these problems.

The results showed that pharmacists regarding psychotropic and narcotic dispensing without a prescription tended not to break the rules, but they did so regarding the fate of prescription after dispensing. The majority of participating pharmacists tended to neither keep the prescription, nor have a record for dispensed psychotropic medications. From this study it was concluded that pharmacists may have a lack of knowledge and loose of attitude regarding psychotropic dispensing laws. Educational programs and training of pharmacist must be taken into consideration.

\section{Introduction:-}

It is well known how psychotropic and narcotic drugs affect mood and behavior and can cause drug dependence (Rang, Ritter, Flower, \& Henderson, 2014). Also Most sedatives, CNS stimulants, and narcotic drugs are well known for the withdrawal symptoms they cause after abstinence (Rang et al., 2014). Though opioid analgesics, stimulants, and psychotherapeutic drugs are strictly prescribed, research has shown that they are among the most widely misused and abused prescribed and over-the-counter (OTC) medications (Lord et al., 2009). And in this regard, pharmacists have a pivotal role in the control of these drugs.

Corresponding Author:-ArwaBenkhaial.

Address:-Lecturer at Department of Pharmacology and Toxicology, Faculty of Pharmacy, University of Benghazi. 
The United States National Institute on Drug Abuse (NIDA) in 2011 estimated that approximately $2.8 \%$ of the population was using psychotherapeutic drugs for nonmedical purposes (Jaber, Bulatova, Suyagh, Yousef, \& Wazaify, 2015). Similar results were confirmed by many researchers through the Middle East area (Albsoul-Younes, Wazaify, Yousef, \& Tahaineh, 2010; Lord et al., 2009; Sweileh et al., 2004). Even medicines containing psychoactive drugs prescribed for medical reasons are sometimes overused by patients (Radat, Irachabal, Swendsen, \& Henry, 2002).

The World Health Organization (WHO) has issued a document titled " Guidelines for the Control of Narcotic and Psychotropic Substances". It included the responsibilities of different parties under the international drug control treaties. Based on this document, the aim of these international treaties was to limit the use of controlled substances to medical and scientific purposes and to assist governments in their efforts to prevent drug abuse. In this convention, it was agreed that the great majority of these substances can be dispensed or supplied to individuals only on a medical prescription signed by a physician. Due to the liability of these substances to produce dependence and abuse, it is recommended as a general safety precaution for their use, that prescriptions are restrained with regard to the number of times they may be refilled and the duration of their validity, as this will protect the public health and welfare. Therefore, certain minimum information should be recorded on a prescription for a psychotropic substance, namely: information of the prescriber as well as the patient, prescription date, and the preparation type, strength and amount (Rexed, 1984). For the control of narcotic, the guidelines may require some extra information to be provided, including the directions for use, refill information and the signature of the doctor. Many countries find control easier if a prescription for such drugs cannot be repeated. Other simple identifiers, such as an official prescriber's reference number or stamp, are used. The duration of validity of a prescription for a narcotic or psychotropic substance is frequently specified in drug regulations, while the maximum quantities to be prescribed may also be laid down (Rexed, 1984).

Each country has its own laws and guidelines for controlling narcotic and psychotropic drugs' use. The Libyan law has a group of rules for controlling the use and dispensing of narcotic and psychotropic drugs, which are mentioned in the law Number (7) for the year 1990 about Narcotics and Psychotropic drugs (The Libyan Ministry of Justice, 2015). This is a national law of the "State of Libya" that controls all aspects regarding these drugs, such as, production, import, export, possession, and others. This law includes some articles that organize the prescribing and dispensing of these drugs in hospitals, pharmacies and other healthcare facilities. Wherefore, the pharmacist is in the core of these processes, and hence, should be aware of these laws and have enough knowledge about them. Namely the articles XVI, XVIII, XIX, XX, that are of concern to our study.

As known pharmacists are the most accessible front-line members of the healthcare delivery community. Unfortunately, they also appear to be a major source through which consumers can obtain prescription drugs nonmedically.(Murthy, P. Swaroop HS, 2016). Additionally, as the problem of drug abuse is growing, as elsewhere, in the last years (Elamouri et al., 2017). Therefore, pharmacists should have good knowledge about the rules that control the dispensing of psychotropic and narcotic medication. Moreover, they should take an attitude that shows respect to these rules and practice them in their daily work. Hence, the general aim of this study was to highlight the role of Libyan pharmacists in the problem of psychotropic and narcotic drug misuse in Libya and measures the knowledge, attitude, and practices of Libyan pharmacists towards rules of psychotropic and narcotic drugs dispensing.

\section{Methods:-}

Firstly, a draft of the questionnaire was piloted on convenience of 7 practicing pharmacists to check for readability, understanding, question design and the length of the questionnaire. After that, based on the result of this pilot study, the questionnaire was used with some modifications and the final questionnaire was applied. An online crosssectional survey of pharmacists in Libya was conducted over a period of 6 months from August/2016 to February/2017. This online structured questionnaire was built using the "Google Forms" (Google(C), 2016) application. This application collected the data and analyzed them.

This online questionnaire was spread in two languages English and Arabic using social network groups that contained a total of 10,000 pharmacists. The questionnaire consisted of a series of questions where all of them were of closed multiple-choice type. The questionnaire included 10 items about the dispensing of psychotropic drugs and demographic information of the pharmacist. The first four questions were about age, gender, degree, and the experience of the respondents. Sixth to tenth were made up of scenario-based questions. The purpose of these 
questions was to find out how often certain problems regarding psychotropic drugs dispensing occurred in pharmacy practice and how pharmacists dealt with these problems. The questions consisted of different daily situations that may face the pharmacist and what would the pharmacist do to tackle them and how he/she would deal with these situations.

Then the questionnaire was distributed to pharmacists online. The survey responses were treated and the data from all the respondents were analyzed by "Google forms".

Descriptive statistics include percentages and frequency distribution were calculated for each of the variables.

\section{Results:-}

268 respondents have responded to this questionnaire. The demographic data of the responding pharmacists reveal that the majority of the respondents are young adults (from the age group of 20-30 years) who contributed about $75 \%$ of the respondents, while older age groups (older than 50 years) were only $1.5 \%$. About $70 \%$ of the respondents were females, and males comprised only around 30\%. Around 59\% of the responding pharmacists had a Bachelor degree and $7 \%$ were pharmacy assistants.

The majority of respondents had a work experience of less than 5 years (69\%), and about $24 \%$ had an experience of work from 5-10 years. The detailed demographic data are shown in Table(1).

Table 1:-Socio-demographic data

\begin{tabular}{|c|c|}
\hline Parameters & $\mathrm{N}(\%)$ \\
\hline \multicolumn{2}{|l|}{ Ages (years) } \\
\hline $20-30$ & $200(74.6 \%)$ \\
\hline $30-40$ & $57(21.2 \%)$ \\
\hline $40-50$ & $7(2.61 \%)$ \\
\hline$>50$ & $4(1.5 \%)$ \\
\hline \multicolumn{2}{|l|}{ Gender } \\
\hline Male & $81(30.22 \%)$ \\
\hline Female & $187(69.77 \%)$ \\
\hline \multicolumn{2}{|l|}{ Qualification } \\
\hline Student & $69(25.7 \%)$ \\
\hline Bachelor & $157(58.6 \%)$ \\
\hline Diploma & $19(7 \%)$ \\
\hline Master & $16(6 \%)$ \\
\hline $\mathrm{PhD}$ & $7(2.61 \%)$ \\
\hline \multicolumn{2}{|l|}{ Experience } \\
\hline Less than 5 years & $184(68.65 \%)$ \\
\hline $5-10$ years & $64(23.88 \%)$ \\
\hline $10-20$ years & $16(6 \%)$ \\
\hline$>20$ & $4(1.5 \%)$ \\
\hline
\end{tabular}


$74 \%$ of the respondents answered the first question, which was about dispensing an anxiolytic drug without a prescription, with NO. And 11\% would dispense the medicine (Xanax) without a prescription, while 15\% declared that they might do so. Figure (1) shows the distribution of respondents after asked about dispensing an anxiolytic without a prescription. A majority of the respondents $(66 \%)$ said that they would not dispense "Prozac" without a prescription, while 14\% stated that they will do. Figure (2) illustrates the percentages of responding pharmacists after being asked about an Antidepressant without a prescription.

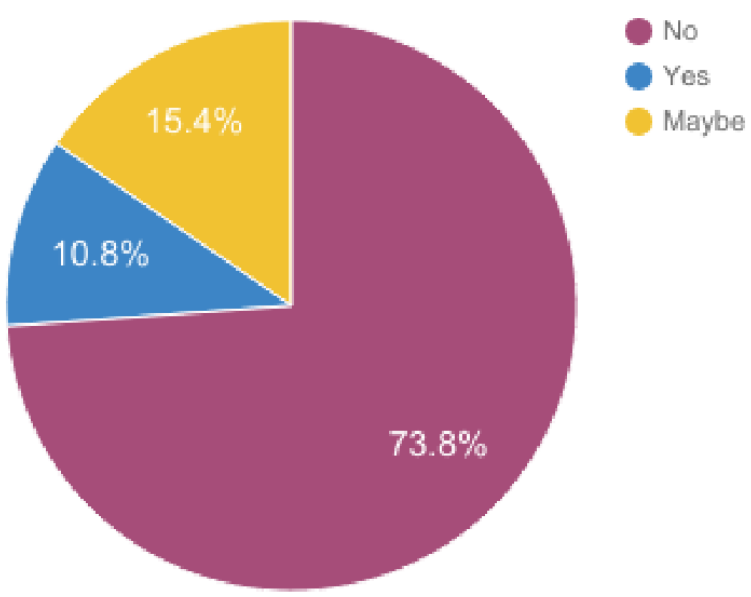

Figure 1:-Dispensing an Anxiolytic drug without a prescription

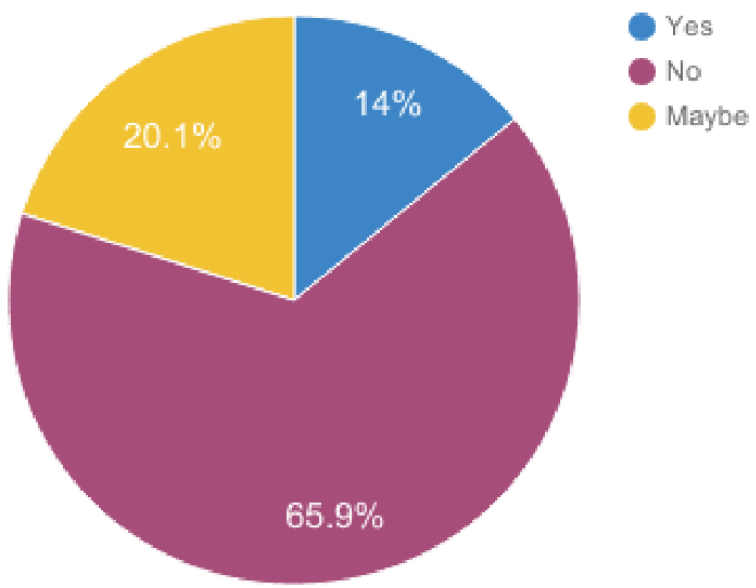

Figure 2:-Dispensing an Antidepressant without a prescription

Regarding the refilling of an old prescription, the greater part (55\%) of the respondents exclaimed that they would not do so, whereas $27 \%$ might do. Figure (3) shows the distribution of respondents asked about refilling an old prescription.

The fourth question was concerning the "fate" of prescriptions of psychotropic drugs, e.g., Lithium. In this regard, $23 \%$ of the respondents would simply just return the prescription to the patient. On the other hand, the rest of the respondents would sign it, record it and either return it (43\%) or keep it (33\%). Figure (4) demonstrates the percentages of responding pharmacists when asked about the fate of the prescription after dispensing it.

Asking about the practice of keeping a record of dispensed psychotropic drugs, the common practice was not keeping one (59\%), but the rest of the respondents did. Figure (5) illustrates the distribution of pharmacists keeping a record for dispensed psychotropic and narcotic drugs. 


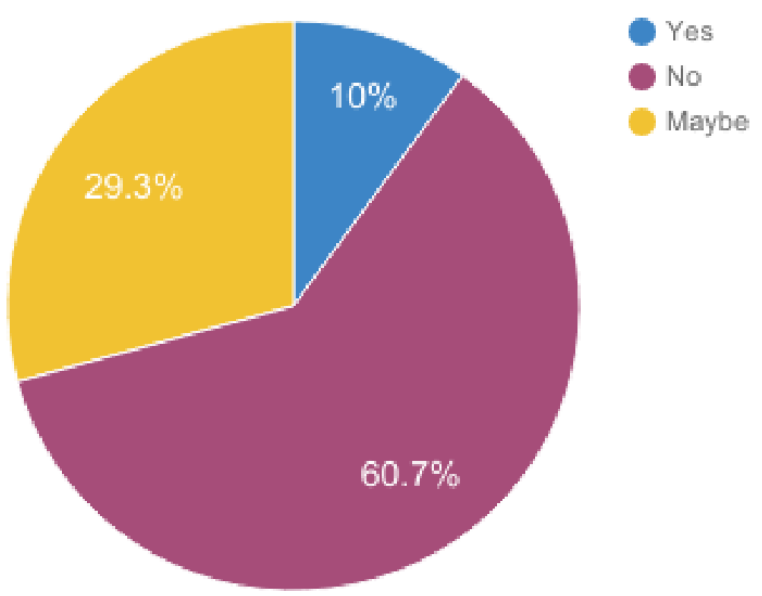

Figure 3:-Refilling an old prescription

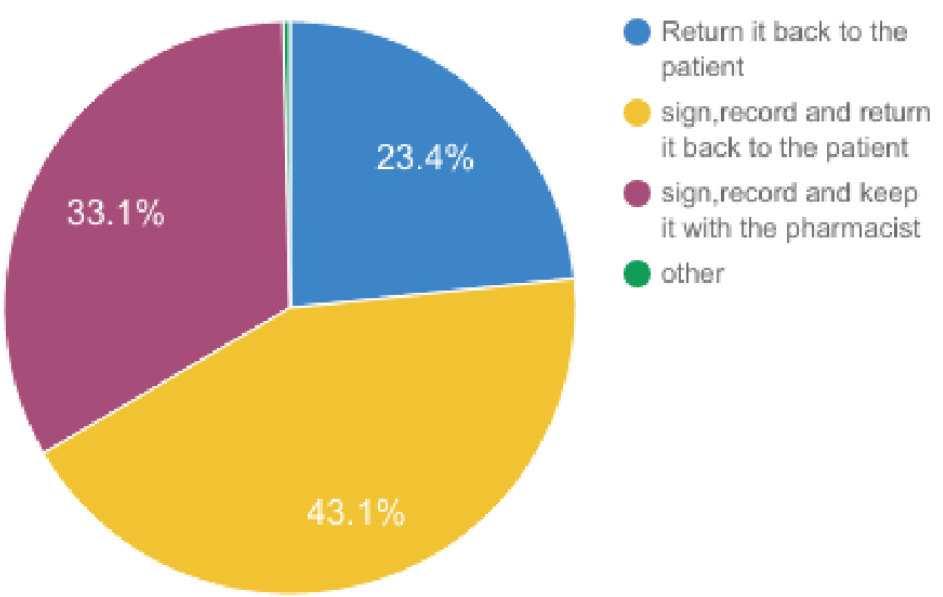

Figure4:-The fate of the prescription after dispensing

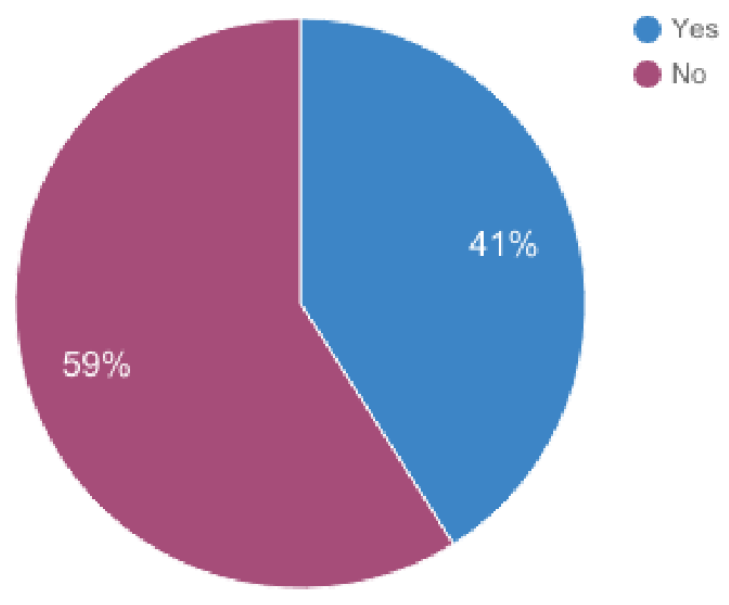

Figure 5:-Recording of Dispensed Psychotropic or narcotic drug

When asked about " the kind of record" they used, it was paper and electronic record $34 \%$ and $29 \%$ respectively. Figure (6) shows the method for registering the psychotropic and narcotic drug prescription information. 


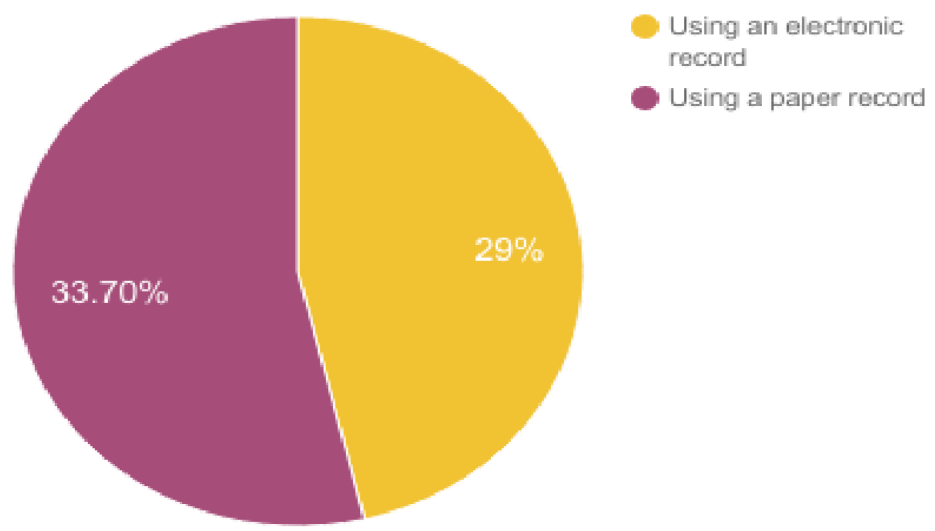

Figure 6:-The method for registering the psychotropic drug prescription

The last question was about "what kind of information they register?" and the answers are shown in Figure 7 and Table 2 .

Table 2:-The registered information after drug dispensing

\begin{tabular}{|l|c|}
\hline Type of information & $\mathrm{N}$ \\
\hline Patients information & $11 \%$ \\
\hline $\begin{array}{l}\text { Drug information } \\
\text { Date of the } \\
\text { prescription }\end{array}$ & $27.6 \%$ \\
\hline $\begin{array}{l}\text { Prescribes } \\
\text { information }\end{array}$ & $13.8 \%$ \\
\hline All of the above & $4.10 \%$ \\
\hline Others & $51.86 \%$ \\
\hline
\end{tabular}

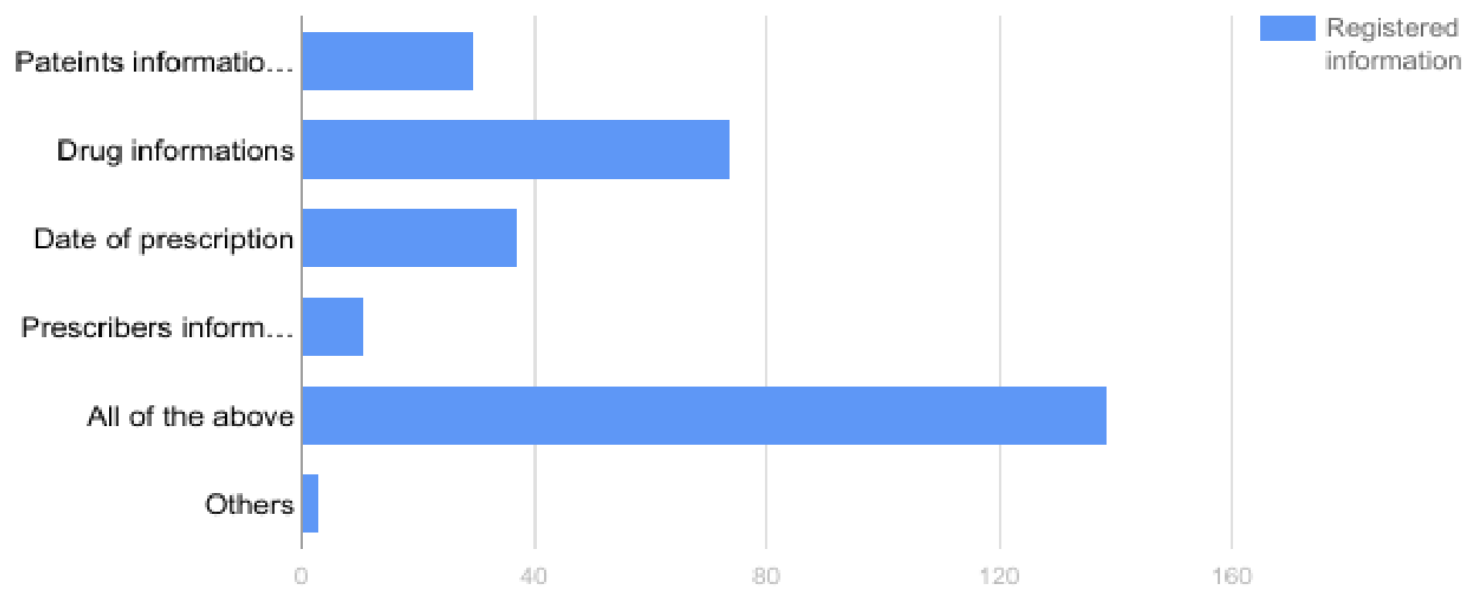

Figure 7:-The information registered after dispensing 


\section{Discussion:-}

The likelihood of psychotropic and narcotic drugs to be abused and misused is well documented. Hence, many laws and rules are elaborated nationally and internationally to control their dispensing. In this study, it was intended to investigate the knowledge, attitude, and practice of Libyan pharmacists towards enacted national laws that control the dispensing of psychotropic and narcotic drugs.

The questionnaire included some examples of breaking the rules, e.g. to supply medication without a prescription to a patient who had run out of his/her medicine, or refill an old prescription, and respondents were asked to answer what they would do in these situations.

In this study, It was evident that the respondents tended not to break the rules, and only a small percentage of them had the tendency to do so. This was mainly seen in the first and second circumstances, i.e., dispensing an anxiolytic and antidepressant without a prescription. This is unlike the findings of a previous study that has been done in Saudi Arabia, where $89.5 \%$ of the pharmacists dispensed an antipsychotic simply by following the collaborator's request without even asking for a doctor's prescription (Al-Mohamadi, Badr, Bin Mahfouz, Samargandi, \& Al Ahdal, 2013).

In the case of refilling an old prescription, most of the responding pharmacists have shown that they have a good knowledge of the law that prevents doing so. This is comparable to a study conducted in Bangalore that showed that $90 \%$ of participants reported that they had obtained their medications at the chemist's stores in the previous 12 months by showing an outdated prescription (Murthy, P. Swaroop HS, 2016).

On the contrary, the majority of the respondents were likely not to comply with the rule of keeping the prescription after filling it. This could be due to lack of knowledge or it may imply a "loose" attitude of those pharmacists towards this rule. This was seen also in another study conducted in Indonesia about (39\%) not only dispensed the medicines but also returned prescription back to the patients (Puspitasari, Faturrohmah, \& Hermansyah, 2011).

Surprisingly, it seems that the majority of respondents do not register any information of the psychotropic or narcotic drugs they dispense. In another study in Pakistan about the compliance with legal requirements at community pharmacies showed that none of the pharmacies completely complied with the legal requirements in terms of documentation, narcotics section. (Hussain, Ibrahim, \& Baber, 2012).

From those who register the required information, it is worth to be mentioned that about $29 \%$ use electronic records, which are a good tool to store, reimburse patient drug information, even those related to drug abuse (Ghitza, Ghitza, Sparenborg, \& Tai, 2011). And the great part of them seem to practice registering most of the required information after dispensing.

From what has been noticed in the first three questions the pharmacists tended not to break the rules, this can be due to previous knowledge about the effects of psychotropics, though previous studies have shown that practicing pharmacists lack the required knowledge about topics related to abused drugs (Jaber et al., 2015). But in the rest of the questions they tend to break them, this shows that there is a gap between the answers which may indicate that there is a lack of knowledge of rules, laws and issues regarding psychotropics dispensing, or the answers of some questions were not realistic.

Our research project can be expanded and be part of further studies of educating pharmacists and monitoring their practices of drug dispensing. Generally, an online questionnaire has the advantage that the respondents feel more comfortable answering the questions anonymously, where they would answer more freely and the answer may be more reliable. Another characteristic of this questionnaire is that we have decided to use "scenario based" questions. The reason for this is to ensure that participants feel free to answer the questions without any sense of judgment. Also online surveys are less time consuming and require less logistics. On the other hand, this study had numerous disadvantages. Firstly, being an online survey study would not make us sure about the credibility of the answers, e.g., some of the respondents could be not pharmacists at all. Secondly, the survey was formulated with closedended questions, which have lower validity rate than other question types, e.g. open-ended questions. Additionally, survey question answer options could lead to unclear data because certain answer options may be interpreted differently by respondents. In this regard, it is to mention, that closed questions had another drawback that the respondents were not able to give reasons that may justify their practice. In such cases, participants may speak of rule breaking as the responsible thing to do, and it would be framed by participants in terms of acting professionally. 
As professionals, pharmacists sometimes use their judgments in individual cases where guidelines do not exist, or are regarded as inappropriate (Deans, 2010).

Another important drawback of this study is the small number of respondents in comparison to the number of the population of pharmacists in Libya, which may render it to be not representative, but this was due to the low response rate of pharmacists, which also indicates a negative attitude towards research.

\section{Conclusion:-}

This study aimed to explore the knowledge, attitude, and practices of local pharmacists in Libya towards adhering to the Libyan legal regulations of psychotropic and narcotic drugs' dispensing. In general, Libyan pharmacists seem to have an acceptable level of knowledge, but a loose attitude towards dispensing psychotropic drugs in relation with Libyan laws and regulations. This was evident in the gap between the answers of questions, where they seemed to not really practice these rules during dispensing.

We recommend implementing regular educational programs to increase the levels of knowledge and awareness among local pharmacists towards the negative impact and serious consequences of such drugs on patient's health and life. According to the American Association of Colleges of Pharmacy advocates that pharmacists can have a significant impact on substance abuse prevention provided they receive adequate training. Continuing education programs are needed to enable practicing pharmacists to augment their limited education (Continuing education for pharmacists on substance abuse prevention), thus guidelines for controlling psychotropic and narcotic drugs must be included in the undergraduate study. Workshops and educational programs on the growing problem of drug abuse and misuse in Libya must be held. Post graduate training must be taken into consideration especially in psychotropics and narcotics dispensing and prescribing, educating teenagers and young adults to increase their knowledge about the effects of psychoactive drugs, and drug abuse and misuse.

Moreover, the use of electronic records worldwide lowered the problem of psychotropic drug abuse and misuse. Electronic records should be used in Libya to limit the growing problem of drug abuse. Also activating the laws for drug dispensing should be done as soon as possible.

\section{References:-}

1. Al-Mohamadi, A., Badr, A., Bin Mahfouz, L., Samargandi, D., \& Al Ahdal, A. (2013). Dispensing medications without prescription at Saudi community pharmacy: Extent and perception. Saudi Pharmaceutical Journal, 21(1), 13-18. https://doi.org/10.1016/j.jsps.2011.11.003

2. Albsoul-Younes, A., Wazaify, M., Yousef, A. M., \& Tahaineh, L. (2010). Abuse and misuse of prescription and nonprescription drugs sold in community pharmacies in Jordan. Substance Use and Misuse, 45(9), 1319-1329. https://doi.org/10.3109/10826080802490683

3. Deans, Z. (2010). Ethics in pharmacy practice University of Bristol. Retrieved from http://pharmacyresearchuk.org/wpcontent/uploads/2012/11/Ethics_in_pharmacy_practice_200910.pdf

4. Elamouri, F. M., Musumari, P. M., Techasrivichien, T., Farjallah, A., Elfandi, S., Alsharif, O. F., ... Kihara, M. (2018). "Now drugs in Libya are much cheaper than food": A qualitative study on substance use among young Libyans in post-revolution Tripoli, Libya. International Journal of Drug Policy, 53, 23-31. https://doi.org/10.1016/j.drugpo.2017.11.026

5. Ghitza, U., Ghitza, U., Sparenborg, S., \& Tai, B. (2011). Improving drug abuse treatment delivery through adoption of harmonized electronic health record systems. Substance Abuse and Rehabilitation, 125. https://doi.org/10.2147/sar.s23030

6. Hussain, A., Ibrahim, M. I. M., \& Baber, Z. U. D. (2012). Compliance with legal requirements at community pharmacies: A cross sectional study from Pakistan. International Journal of Pharmacy Practice, 20(3), 183-190. https://doi.org/10.1111/j.2042-7174.2011.00178.x

7. Jaber, D., Bulatova, N., Suyagh, M., Yousef, A. M., \& Wazaify, M. (2015). Knowledge, attitude and opinion of drug misuse and abuse by pharmacy students: A cross-sectional study in Jordan. Tropical Journal of Pharmaceutical Research, 14(8), 1501-1508. https://doi.org/10.4314/tjpr.v14i8.25

8. Lord, S., Downs, G., Furtaw, P., Chaudhuri, A., Silverstein, A., Gammaitoni, A., \& Budman, S. (2009). Nonmedical use of prescription opioids and stimulants among student pharmacists. Journal of the American Pharmacists Association, 49(4), 519-528. https://doi.org/10.1331/JAPhA.2009.08027

9. Murthy, P. Swaroop HS, C. A. (2016). Guidelines to Prevent the Misuse of Prescribed Medications. 
Vims.Ac.In. Retrieved from http://www.vims.ac.in/pdf/NIMHANS-Booklet.pdf

10. Puspitasari, H. P., Faturrohmah, A., \& Hermansyah, A. (2011). Do Indonesian community pharmacy workers respond to antibiotics requests appropriately? Tropical Medicine and International Health, 16(7), 840-846. https://doi.org/10.1111/j.1365-3156.2011.02782.x

11. Radat, F., Irachabal, S., Swendsen, J., \& Henry, P. (2002). Analgesic abuse and psychiatric comorbidity in headache patients. [French] \rAbus d'antalgiques et comorbidite psychiatrique chez les cephalalgiques. Encephale, 28(5 I), 466-471. Retrieved from https://europepmc.org/abstract/med/12386550

12. Rang, H., Ritter, J., Flower, R., \& Henderson, G. (2014). Rang \&amp; Dale's Pharmacology E-Book. Retrieved from

https://books.google.com/books?hl=en\&lr=\&id=iOLTBQAAQBAJ\&oi=fnd\&pg=PP1\&dq=Rang+HP,+2007+o n\&ots=bfNbYj56Bo\&sig=pIC_wkK1eF1DblQApXuaJNmbH8A

13. Rexed, B. (1984). Guidelines for the control of narcotic and psychotropic substances: in the context of the international treaties. Retrieved from https://apps.who.int/iris/handle/10665/39299

14. Sweileh, W. M., Zyoud, S. H., Sawalha, A. F., Abu-Taha, A., Hussein, A., \& Al-Jabi, S. W. (2013, December 2). Medical and biomedical research productivity from Palestine, 2002 - 2011. BMC Research Notes. https://doi.org/10.1186/1756-0500-6-41

15. The Libyan Ministry of Justice ( Accessed July 2016 )Available form http://aladel.gov.ly/home/?p=1299. 